\title{
Perancangan Alat Pelindung Diri (APD) Penutup Bahu Dan Lengan Yang Ergonomis Pada Proses Pengelasan Di PT McDermott
}

\author{
M. Ansyar Bora ${ }^{(1)}$, Larisang ${ }^{(2)}$, Dedi Bastian Tarigan ${ }^{(3)}$ \\ (1), (2), (3) Sekolah Tinggi Teknik Ibnu Sina Batam \\ Jl. Teuku Umar Lubuk Baja, Kota Batam, Kepulauan Riau \\ (1)ansyar@stt-ibnusina.ac.id, ${ }^{(2)}$ larisang01@yahoo.co.id, ${ }^{(3)}$ dedi@stt-ibnusina.ac.id
}

\begin{abstract}
ABSTRAK
PT. McDermott Indonesia adalah perusahaan swasta yang bergerak dibidang jasa konstruksi pemasangan instalasi pipa minyak dan gas dari dasar sampai permukaan laut. Pemasangan instalasi pipa minyak ini dilakukan dengan pengelasan, sehingga membutuhkan banyak juru las (welder), para pekerja/juru las ini bekerja hanya mengunakan baju kerja (wearpack) yang tidak tahan terhadap percikan api sehingga mengakibatkan wearpack yang digunakan berlubang, hal ini berdasarkan hasil observasi dilapangan kasus ini banyak di temukan pada bagian lengan dan bahu, sehingga dalam aktifitas pengelasan sering terjadi kecelakaan seperti pembengkakan pada kulit lengan dan bahu akibat terkena percikan api.

Tujuan dari penelitian ini yaitu untuk menghasilkan rancangan Alat Pelindung Diri $(A P D)$ penutup bahu dan lengan dengan menggunakan pendekatan Ergonomi antropometri tubuh. Penelitian ini dilakukan dengan menggunakan 50 sampel yang diperoleh dari hasil uji kecukupan data, dengan menggunakan persentil 95\% maka diperoleh ukuran; a) Lingkaran pergelangan tangan (LPT) $30 \mathrm{~cm}, b)$ Lingkaran Lengan Atas (LLA) $56 \mathrm{~cm}$, c) Lingkaran Leher (LL) $50 \mathrm{~cm}$, d) Panjang Tangan sampai Ketiak (PTK) $61 \mathrm{~cm}$, e) Panjang Tangan sampai Ujung Leher (PTUL) $90 \mathrm{~cm}, \mathrm{f}$ ) Lebar Bahu (LB) $30 \mathrm{~cm}$. Alat Pelindung Diri (APD) Penutup bahu dan lengan ini terbuat dari bahan kulit sapi yang tahan terhadap percikan api sehingga memberikan keamanan bagi juru las.
\end{abstract}

Kata kunci: Antropometri tubuh, Desain Produk APD dan Ergonomis

\section{A. Latar Belakang Masalah}

\section{PENDAHULUAN}

PT McDermott Indonesia (PTMI) Devisi Marine adalah perusahaan swasta yang bergerak dibidang jasa konstruksi pemasangan instalasi pipa minyak dan gas dari dasar sampai permukaan laut. PTMI Devisi Marin Base Batam memiliki pelabuhan kapal sendiri dan mempunyai banyak aktivitas kerja di sekitarnya. Welding Shop Area merupakan tempat pembuatan barang- barang pembantu untuk kegiatan di laut yang bayak terdapat kegiatan pengelasan, diantaranya adalah bagian perbaikan (repair), tempat pembuatan stinger (alat untuk meluncurkan pipa yang telah di sambung kedasar laut), area tempat pengetesan juru las, perbaikan kapal tongkang dan pengelasan alat pembantu lainnya. Sebagian besar peroses pengelasan di dalamnya memiliki standar internasional baik ukuran maupun kualitas.

Jumlah pekerja/juru las (welder) pada PTMI Devisi Marin Base Batam adalah 78 orang pekerja dan rata-rata pekerja melakukan pekerjaan 12 jam perhari. Dalam kegiatan oprasionalnya, pekerja pada perusahaan ini banyak berintraksi dengan mesin-mesin berat, peralatan dan lingkungan kerja yang panas dengan resiko kecelakaan yang tinggi. Dalam menunjang kesehatan dan keselamatan kerja (K3), diperlukan pemakaian Alat Pelinding Diri (APD) yang tepat secara berkesinambungan didalam perusahaan. APD adalah peralatan yang di pakai untuk melindungi pekerja dari seluruh kondisi bahaya yang dapat menimbulkan kecelakaan kerja.

Berdasarkan pengamatan lapangan yang dilakukan pada PT Mc Dermott Indonesia (PTMI) Devisi Marine ditemukan penyakit akibat kerja seperti pembengkakan pada kulit lengan dan bahu akibat terkena percikan api las, hal ini disebabkan karena pekerja/juru las dalam melakukan pengelasan pada posisi overhead (4G) dengan menggunakan APD topeng las yang hanya melindungi muka dan kepala dari percikan api sementara bahu dan lengan tetap terkena percikan 
api, sehingga mengakibatkan baju kerja (wearpack) yang digunakan berlubang, karena baju kerja yang digunakan tidak tahan terhadap percikan api las. APD topeng las yang digunakan belum efektif melindungi pekerja dalam posisi pengelasan overhead (4G) sehingga perlu dirancang APD berupa penutup bahu dan lengan yang tahan terhadap percikan api yang lebih efektif terutama dari segi keamanan dan kenyamanan.

Dalam perancangan alat pelindung diri ini digunakan pendekatan ergonomi antropometri tubuh, antropometri adalah sebuah studi tentang pengukuran tubuh dimensi manusia dari tulang, otot dan jaringan adiposa atau lemak (Survey, 2009). Menurut (Wignjosoebroto, 2008), antropometri adalah studi yang berkaitan dengan pengukuran dimensi tubuh manusia, sehingga dengan menggunakan pendekatan antropetri hasil perancangan produk/alat yang sesuai dengan dimensi tubuh pekerja yang akan menggunakan produk tersebut.

\section{B. Rumusan Masalah}

Berdasarkan latar belakang yang telah dijelaskan, maka dapat dirumuskan masalah sebagai berikut:

1. Bagaimana merancang Alat Pelindung Diri (APD) penutup bahu dan lengan yang ergonomis, dengan pendekatan antropometri tubuh di PT McDermott Indonesia (PTMI) Devisi Marine? (

2. Bagaimana merancang Alat Pelindung Diri (APD) yang dapat mengurangi resiko cedera pada bahu dan lengan juru las?

\section{Tujuan Penelitian}

Tujuan penelitian yang ingin dicapai adalah;

1. Untuk merancang Alat Pelindung Diri (APD) penutup bahu dan lengan yang ergonomis, dengan pendekatan antropometri tubuh di PT McDermott Indonesia (PTMI) Devisi Marine?

2. Untuk merancang Alat Pelindung Diri (APD) yang dapat mengurangi resiko cedera pada bahu dan lengan juru las?

\section{Manfaat Penelitian}

Adapun manfaat penelitian ini sebagai berikut:

1. Mencegah kecelakan kerja pada proses pengelasan dengan posisi overhead (4G)

2. Menghasilkan alat pelindung diri pada proses pengelasan yang lebih aman dan nyaman

3. Meningkatkan keselamatan dan kesehatan kerja dalam proses pengelasan.

\section{A. Waktu dan Tempat Penelitian}

\section{METODOLOGI}

Penelitian tersebut dilakukan dari bulan November 2016 s/d April 2017 di PT McDermott Indonesia Devisi Marine Base Batam.

\section{B. Jenis Data}

Data yang digunakan dalam penelitian ini dikelompokan menjadi dua yaitu :

1) Data Primer, Data primer dalam penelitian ini yaitu data antropometri tubuh yang akan diambil yaitu: a) Lingkaran pergelangan tangan (LPT), b) Lingkaran Lengan Atas (LLA), c) Lingkaran Leher (LL), d) Panjang Tangan sampai Ketiak (PTK), e) Panjang Tangan sampai Ujung Leher (PTUL) dan f)Lebar bahu (LB).

2) Data Sekunder, data sekunder dalam penelitian ini yaitu: a) Buku - buku mengenai ergonomi, b) Buku - buku mengenai Alat Pelindung Diri (APD), c) Buku - buku statistik untuk penelitian

\section{Metode Pengumpulan Data}

Pengumpulan data dilakukan dengan metode observasi dan melakukan pengukuran secara langsung dimensi tubuh pada 50 pekerja/juru las pada PT McDermott Indonesia Devisi Marine Base Batam. 


\section{Metode Pengolahan Data}

Pengolahan data yang dilakukan dalam penelitian ini adalah sebagai berikut:

Uji Keseragaman Data

a. Menghitung rata - rata, dengan menggunakan rumus :

$$
\text { Rumus : } \begin{aligned}
\bar{X} & =\frac{\sum X i}{N} \\
\overline{\bar{x}} & =\frac{\sum X i \text { Bar }}{k}
\end{aligned}
$$

b. Menghitung batas kontrol atas dan batas kontrol bawah dengan rumus :

$$
\begin{aligned}
& \mathrm{BKA}=\overline{\bar{x}}+2 \sigma x \\
& \mathrm{BKB}=\overline{\bar{x}}-2 \sigma x
\end{aligned}
$$

c. Menghitung standar deviasi, dengan menggunakan rumus :

Dimana :

$$
\text { Rumus : } \begin{aligned}
\sigma & =\sqrt{\frac{\sum(X i-\bar{X})^{2}}{N-1}} \\
\sigma x & =\frac{\sigma}{\sqrt{n}}
\end{aligned}
$$$$
X=\text { Nilai rata }- \text { rata. }
$$$$
\sigma=\text { Standar deviasi. }
$$$$
N=\text { Banyaknya data. }
$$$$
\sigma x=\text { Standar deviasi rata }- \text { rata sub grup. }
$$

Uji Kecukupan Data

Uji kecukupan data dapat dilakukan dengan menggunakan rumus sebagai berikut :

$$
\text { Rumus : } N^{\prime}=\left[\frac{k / s \sqrt{N\left(\sum X i^{2}\right)-\left(\sum X i\right)^{2}}}{\sum X i}\right]^{2}
$$

Distribusi Frekuensi

Dimana $: k=$ tingkat keyakinan.

$s=$ derajat ketelitian.

$\mathrm{N}=$ jumlah data pengamatan.

$\mathrm{N}^{\prime}=$ jumlah data teoritis.

Adapun yang akan dihitung dalam distribusi frekuensi antara lain :
a. Range $(\mathrm{R})=($ Data terbesar - Data terkecil $)$
b. Jumlah Kelas $(\mathrm{CI})=1+3,3 \log \mathrm{N}$
c. Panjang Kelas $=\frac{R}{C I}$

Uji Kenormalan Data

a. Mencari $\mathrm{Z}$ untuk setiap batas kelas

$$
\text { Rumus: } \mathrm{Z}_{1}=\frac{X o-\bar{X}}{\sigma x}
$$

b. Mencari luas batas kelas interval $(\mathrm{P})$

$$
\mathrm{P}=\mathrm{Z}_{\max }-\mathrm{Z}_{\min }
$$

c. Mencari nilai frekuensi ekspektasi (E) tiap kelas interval

$$
\text { Rumus : } \mathrm{E}_{1}=\mathrm{P}_{1} \text {. N }
$$

Uji Persentil
a. Persentil $5\left(\mathrm{P}_{5}\right)$, Letak $\mathrm{P}_{5}=\bar{x}-1.645 \sigma x$
b. Persentil $50\left(\mathrm{P}_{50}\right)$, Letak $\mathrm{P}_{50}=\bar{x}$
c. Persentil $95\left(\mathrm{P}_{95}\right)$ Letak $\mathrm{P}_{95}=\bar{x}+1.645 \sigma x$ 


\section{HASIL DAN PEMBAHASAN}

Setelah dilakukan pengumpulan data maka dilakukan uji keseragaman, uji kecukupan, distribusi frekuensi, uji kenormalan dan persentil sebagai berikut:

\section{A. Uji Keseragaman Lingkaran Pergelangan Tangan (LPT)}

Tabel 1 Keseragaman Lingkaran Pergelangan Tangan (LPT)

\begin{tabular}{|c|c|c|c|c|c|c|c|c|}
\hline \multirow{2}{*}{$\begin{array}{c}\text { Sub Grup } \\
(\mathrm{k})\end{array}$} & \multicolumn{5}{|c|}{ Data Pengamatan (cm) } & $\mathrm{Xi}$ & $\begin{array}{c}\mathrm{Xi} \\
\text { Bar }\end{array}$ & $\mathrm{Xi}^{2}$ \\
\cline { 2 - 8 } & 1 & 2 & 3 & 4 & 5 & & & \\
\hline 1 & 22 & 24 & 23 & 26 & 18 & 113 & 22.6 & 2589 \\
\hline 2 & 20 & 29 & 24 & 24 & 27 & 124 & 24.8 & 3122 \\
\hline 3 & 21 & 27 & 24 & 23 & 24 & 119 & 23.8 & 2851 \\
\hline 4 & 18 & 30 & 20 & 24 & 21 & 113 & 22.6 & 2641 \\
\hline 5 & 19 & 24 & 22 & 26 & 22 & 113 & 22.6 & 2581 \\
\hline 6 & 24 & 21 & 26 & 25 & 24 & 120 & 24 & 2894 \\
\hline 7 & 22 & 26 & 23 & 25 & 26 & 122 & 24.4 & 2990 \\
\hline 8 & 23 & 21 & 28 & 22 & 24 & 118 & 23.6 & 2814 \\
\hline 9 & 27 & 26 & 25 & 23 & 30 & 131 & 26.2 & 3459 \\
\hline 10 & 25 & 19 & 29 & 25 & 24 & 122 & 24.4 & 3028 \\
\hline & & & $\mathbf{\Sigma}=$ & $\mathbf{1 1 9 5}$ & $\mathbf{2 3 9}$ & $\mathbf{2 8 9 6 9}$ \\
\hline
\end{tabular}

1. $\mathrm{X}-\operatorname{bar}(\overline{\mathrm{X}})$

$$
\bar{x}=\frac{18+20+20+\cdots .30}{50}=23.9
$$

2. X-bar rata-rata $(\mathrm{X})$

$$
\overline{\bar{X}}=\frac{\sum x i \text { Bar }}{k}=\frac{239}{10}=23.9
$$

3. Varian Sampel $(\sigma)$

$$
\sigma=\sqrt{\frac{(18-23.9)^{2}+(18-23.9)^{2}+\cdots+(30-23.9)^{2}}{50-1}}=8.33
$$

4. Standar Deviasi $(\sigma x)$

$$
\sigma x=\frac{\sigma}{\sqrt{n}}=\frac{8.33}{\sqrt{5}}=3.72
$$

5. Batas Kelas ( BK )

$$
\begin{aligned}
& \mathrm{BKA}=\overline{\bar{x}}+2 \sigma x=23.9+(2 * 3.72)=31.34 \\
& \mathrm{BKB}=\overline{\bar{x}}-2 \sigma x=23.9-(2 * 3.72)=16.46
\end{aligned}
$$

Dari hasil perhitungan BKA dan BKB dari dimensi tubuh Lingkaran Pergelangan Tangan (LPT) ternyata semua data masuk dan berada dalam batas kontrol sehingga tidak ada data yang terbuang.

\section{B. Uji Kecukupan Data Lingkaran Pergelangan Tangan (LPT).}

$$
N^{\prime}=\left[\frac{2 / 0,05 \sqrt{50(28969)-(1428025)}}{1195}\right]^{2} N^{\prime}=22.84
$$

Data pengamatan sebenarnya sudah cukup karena memenuhi syarat $N^{\prime}<N$, maka tidak dibutuhkan pengambilan data lagi.

\section{Distribusi Frekuensi Lingkaran Pergelangan Tangan (LPT)}

1. Rentang Kelas (R)

Range $(\mathrm{R})=$ data terbesar - data terkecil $=30-18=12$

2. Jumlah Kelas $(\mathrm{Cl})$ 
Jumlah Kelas $(\mathrm{CI})=1+3.3 \log \mathrm{N}=1+3.3 \log 5=6.61 \sim 7$

3. Panjang Kelas (P)

Panjang Kelas $=\frac{R}{C I}=\frac{12}{7}=1,71$

\section{Uji Kenormalan Data (LPT)}

1. Mencari Z Untuk Setiap Batas Kelas

$$
\begin{aligned}
& \mathrm{Z}_{1}=\frac{0-\overline{\bar{x}}}{\sigma x}=\frac{17.95-23.9}{3.72}=-1.60=1-0.4452 \sim 0.5548 \\
& \mathrm{Z}_{2}=\frac{x 1-\overline{\bar{x}}}{\sigma x}=\frac{19.71-23.9}{3.72}=-1.11=1-0.3665 \sim 0.633 \mathrm{dst} . . .
\end{aligned}
$$

2. Mencari Luas Batas Kelas Interval

$$
\begin{aligned}
& \mathrm{P}_{1}=\mathrm{Z}_{2}-\mathrm{Z}_{1}=0.6335-0.5548=0.0787 \\
& \mathrm{P}_{2}=\mathrm{Z}_{3}-\mathrm{Z}_{2}=0.7676-0.6353=0.1341 \text { dst } \ldots
\end{aligned}
$$

3. Mencari Nilai Frekuensi Ekspektasi Tiap Kelas Interval

$$
\begin{aligned}
& \mathrm{E}_{1}=\mathrm{P}_{1} . \mathrm{N}=0.0787 * 50=3.935 \\
& \mathrm{E}_{2}=\mathrm{P}_{2} . \mathrm{N}=0.1341 * 50=6.705 \text { dst.. }
\end{aligned}
$$

Tabel 2 Distribusi Normal Lingkaran Pergelangan Tangan (LPT)

\begin{tabular}{|l|c|c|c|c|c|c|c|}
\hline Interval Kelas & $\mathbf{Z}$ & $\mathbf{P}$ & $\mathbf{E i}$ & $\mathbf{O i}$ & $(\mathbf{O i}-\mathbf{E i})$ & $(\mathbf{O i}-\mathbf{E i})^{\mathbf{2}}$ & $(\mathbf{O i}-\mathbf{E i})^{2} / \mathbf{~ E i}$ \\
\hline $18.00-19.71$ & 0.6335 & 0.0787 & 3.935 & 16 & 12.065 & 145.56423 & 36.9921792 \\
\hline $19.81-21.52$ & 0.7676 & 0.1341 & 6.705 & 0 & -6.705 & 44.957025 & 6.705 \\
\hline $21.62-23.33$ & 0.9443 & 0.1767 & 8.835 & 9 & 0.165 & 0.027225 & 0.00308149 \\
\hline $23.43-25.14$ & 0.1368 & -0.8075 & -40.375 & 0 & 40.375 & 1630.1406 & -40.375 \\
\hline $25.24-26.95$ & 0.2967 & 0.1599 & 7.995 & 20 & 12.005 & 144.12003 & 18.0262695 \\
\hline $27.05-28.76$ & 0.4066 & 0.1099 & 5.495 & 0 & -5.495 & 30.195025 & 5.495 \\
\hline $28.86-30.57$ & 0.4649 & 0.0583 & 2.915 & 5 & 2.085 & 4.347225 & 1.49132933 \\
\hline \multicolumn{1}{|c|}{ total } & $\mathbf{3 . 6 5 0 4}$ & $\mathbf{- 0 . 0 8 9 9}$ & $\mathbf{- 4 . 4 9 5}$ & $\mathbf{5 0}$ & $\mathbf{5 4 . 4 9 5}$ & $\mathbf{1 9 9 9 . 3 5 1 4}$ & $\mathbf{2 8 . 3 3 7 8 5 9 5}$ \\
\hline
\end{tabular}

Untuk mencari $\mathrm{X}_{\text {hit }}=\frac{\sum(F o i-E i)^{2}}{E i}=\mathbf{2 8 . 3 3 7}$, Untuk menentukan $\mathrm{X}_{\text {tab }}=(1-\propto ; \mathrm{k}-\mathrm{p})=1.635$

Kesimpulan : $\mathrm{X}_{\text {hit }}^{2}>\mathrm{X}_{\text {tab }}^{2}=28.337>1.635$, Maka data tersebut menunjukkan terdistribusi dengan normal.

\section{E. Uji Persentil Lingkaran Pergelangan Tangan (LPT)}

1. Persentil 5

Letak $\mathrm{P}_{5}=\bar{x}-1.645 \sigma x=17.79 \mathrm{~cm}$

2. Persentil 50

Letak $\mathrm{P}_{50}=\bar{x}=23.9 \mathrm{~cm}$

3. Persentil 95

Letak $\mathrm{P}_{95}=\bar{x}+1.645 \sigma x=30 \mathrm{~cm}$

Untuk data antropometri LLA, LL, PTK dan PTUL juga dilakukan uji keseragaman, uji kecukupan, distribusi frekuensi, uji kenormalan dan persentil seperti data antropometri LPT.

Alat Pelindung Diri (APD) Penutup bahu dan lengan yang ergonomis ini, dirancang berdasarkan ukuran data antropometri yang diambil dari 50 responden pekerja/juru las di PT Mc Dermott Indonesia Devisi Marine Base Batam. Persentil yang digunakan dalam peracangan produk APD penutup bahu dan lengan yaitu persentil $95 \%$ pemilihan persentil ini yaitu untuk memungkinkan hampir seluruh pekerja dapat menggunakan produk yang dihasilkan. Adapun ukuran APD penutup bahu dan lengan yaitu: 1) Lingkaran pergelangan tangan (LPT) digunakan untuk menentukan ukuran penutup dibagian pergelangan tangan, ukurannya yaitu $30 \mathrm{~cm}$. 2) Lingkaran Lengan Atas (LLA) digunakan untuk menentukan ukuran lingkaran penutup bagian lenagan atas, ukurannya yaitu $56 \mathrm{~cm}$. 3) Lingkaran Leher (LL) digunakan untuk menentukan ukuran ideal killing lingkaran leher, agar tali yang akan di lilitkan di leher yang tersambung ke penutup bahu dan lengan dapat melekat dengan baik 
sehingga menimbulkan rasa nyaman. Tali ini mempunyai setelan sehingga penguna dapat mengatur sendiri kekencangan dari ikatan sesuai dengan kenyamanan yang di inginkan. Ukurannya yaitu $50 \mathrm{~cm}$. 4) Panjang Tangan sampai Ketiak (PTK) digunakan untuk menentukan panjang ideal penutup pergelangan tangan sampai ketiak. Ukurannya yaitu 61 $\mathrm{cm}$. 5) Panjang tangan sampai ujung leher (PTUL) digunakan untuk menentukan panjang penutup dari pergelangan tangan sampai ujung leher. Ukurannya yaitu $90 \mathrm{~cm}$. 6) Lebar Bahu (LB) digunakan untuk menentukan berapa lebar bahu yang akan ditutup. Ukurannya yaitu $30 \mathrm{~cm}$.

Alat Pelindung Diri (APD) penutup bahu dan lengan ini dapat melindungi pekerja karena terbuat dari bahan kulit yang tahan terhadap percikan api las sehingga pekerja terhindar dari resiko cedera pada proses pengelasan. Berdasarkan rekapitulasi hasil perhitungan persentil $95 \%$ pada tabel 1 diatas, maka dapat di gambarkan prototype APD penutup langan dan bahu yang akan di rancang dapat dilihat pada gambar 1 sebagai berikut:

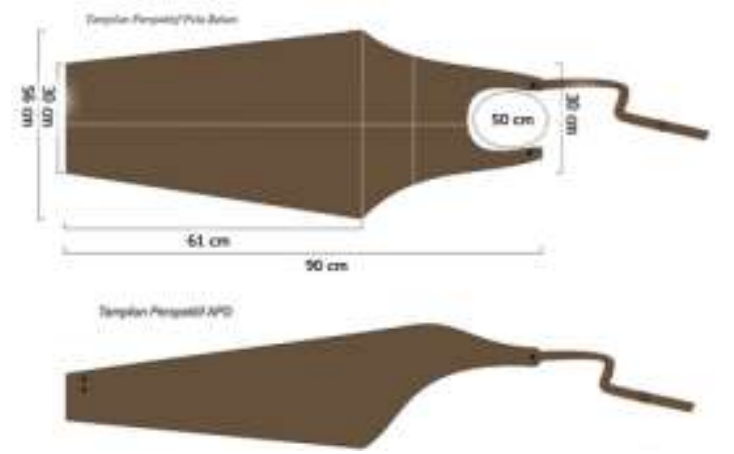

Gambar 1 Prototype APD penutup bahu dan lengan

\section{KESIMPULAN}

1. Persentil yang digunakan dalam peracangan produk APD penutup bahu dan lengan yaitu persentil 95\%, pemilihan persentil ini yaitu untuk memungkinkan hampir seluruh pekerja dapat menggunakan produk tersebut, adapun ukuran APD penutup bahu dan lengan hasil rancangan yaitu; a) Lingkaran pergelangan tangan (LPT) $30 \mathrm{~cm}$, b) Lingkaran Lengan Atas (LLA) $56 \mathrm{~cm}$, c) Lingkaran Leher (LL) $50 \mathrm{~cm}$, d) Panjang Tangan sampai Ketiak (PTK) $61 \mathrm{~cm}$, e) Panjang Tangan sampai Ujung Leher (PTUL) $90 \mathrm{~cm}$, f) Lebar Bahu (LB) $30 \mathrm{~cm}$.

2. Alat Pelindung Diri (APD) Penutup bahu dan lengan ini terbuat dari bahan kulit sapi yang tahan terhadap percikan api sehingga memberikan keamanan bagi juru las.

\section{DAFTAR PUSTAKA}

Afrizal, Safirin, Evaluasi Dan Perbaikan Rancangan Topeng Las Berbasis Studi Ergonomi Dan K3, Institud Teknologi Bandung: 2006.

Aries Kurniawan, Perancanagan Ulang Alat Pelindung Diri (APD) Peroses Pengelasan Denan Pendekatan K3 Dan Ergonomi, Fakultas Teknologi Industri, Surabaya: 2009.

Hanafie Ahmad., 2014, "Pengembangan Mesin Perontok Padi (Combine Harverter) yang Ergonomis Untuk Meningkatkan Produksi", dalam M Sarifuddin (Editor), Jurnal Iltek, Vol 9 No. 18, hlm. 1248-1251, Indonesia: Universitas Islam Makassar

Siswanto, J., 1995, Ergonomi Antropometri, Laboratorium Perancangan Sistem Kerja dan Ergonomi Jurusan teknik Industri - Fakultas Teknologi Industri, ITB, Bandung.

Surya Roberta Zulfhi, Wardah Siti; Hasanah Hikmatul, 2013, "Penggunaan Data Antropometri dalam Evaluasi Ergonomi Pada Tempat Duduk Penumpang Speed Boat Rute Tembilahan-Kuala Enok Kab, Indragiri Hilir Riau", Jurnal MIEJ, Vol 2 No. 1, hlm. 4-8, Indonesia

Tarwaka dkk, 2004, Ergonomi Untuk Keselamatan, Kesehatan Kerja dan Produktifitas, Uniba Press, Surakarta, Indonesia.

Prasetyo Eko, Suwandi Agri, 2011, "Rancangan Kursi Operator SPBU yang Ergonomis dengan Menggunakan Pendekatan Antropometri" Prosiding Seminar Nasional dan Workshop Pemodelan dan Perancangan Sistem, hal. 169-177, Indonesia: Universitas Katolik Parahyangan bandung. 


\section{PERNYATAAN ORISINALITAS KARYA ILMIAH}

Saya yang bertandatangan dibawah ini:

Nama

Alamat

Instansi

No. Identitas (KTP/SIM)
: M. Ansyar Bora

: Perum Palem Raya Blok A2/03, Kota Batam, Kepulauan Riau.

: Sekolah Tinggi Teknik Ibnu Sina Batam

: 2171101004870002

dengan ini menyatakan bahwa karya ilmiah yang akan dipresentasikan dalam Kongres VIII BKSTI - SNTI dan SATELIT dengan judul:

Perancangan Alat Pelindung Diri (APD) Penutup Bahu Dan Lengan Yang Ergonomis Pada Proses Pengelasan Di PT McDermott.

adalah benar-benar karya asli kami dan belum pernah dipublikasikan dalam bentuk jurnal atau bentuk lain yang dapat dipublikasikan secara umum. Kami akan bersedia menanggung segala konsekuensi jika di kemudian hari ada pihak yang merasa dirugikan dan melakukan tuntutan baik secara pribadi maupun secara hukum.

Demikian pernyataan ini kami buat dengan benar serta penuh tanggung jawab.

Batam, 1 Juli 2017

Yang menyatakan

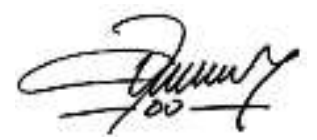

(M. Ansyar Bora) 